J. clin. Path., 22, suppl. (Ass. clin. Path.), 2, 32-41

\title{
Glycogen storage diseases
}

\author{
ROBERT MAHLER
}

From the Department of Metabolic Medicine, Welsh National School of Medicine, Cardiff

The glycogen storage diseases are disorders of glycogen metabolism in which an excessive amount of glycogen accumulates in several tissues. The presence of an excessive amount of glycogen may physically interfere with the function of the tissue but many of the clinical features of the various types of glycogen storage diseases are due directly or indirectly to the impairment of carbohydrate metabolism.

Claude Bernard first isolated glycogen from the liver in 1857 and described its chemical and physiological properties. A little over 70 years later, two forms of glycogen storage disease were recognized: in one form, glycogen was present in large amounts in almost all the tissues of the body, including the heart and tongue, while in the other the excess of glycogen was restricted to the liver and kidney. In spite of much ingenious speculation, no headway was made in the understanding of these disorders until 1952 when Cori and Cori demonstrated the absence of the enzyme glucose 6-phosphatase in the liver of children suffering from the hepatorenal type of glycogen storage disease. Since then, at least five other types of glycogen storage disease have been reliably recognized and classified on the basis of specific enzyme defects related to glycogen metabolism (Table I).

\section{THE GLYCOGEN MOLECULE}

The glycogen molecule is composed of over 120,000 glucosyl units linked together in such a way that it

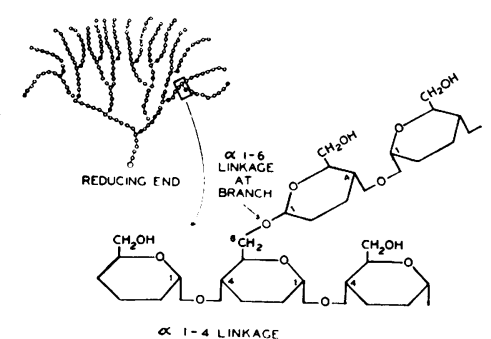

FIG. 1. Formation of branched glycogen molecule.

assumes a tree-like appearance with relatively long inner chains, consisting of up to 20 glucosyl moieties, and shorter outer chains of eight to 12 glucosyl groups branching off from the inner chains (Fig. 1). The glycogen molecule is large enough to be visualized under the electron microscope: it is roughly spherical in shape with a molecular weight of $20 \times 10^{6}$ and a volume of 200 cubic Angstroms but, depending upon the nutritional state, it may aggregate with other glycogen molecules into even larger particles. Glycogen particles are usually present in the cytoplasm, but they also occur in the lysosomes, and in certain pathological conditions may be seen in the nucleus and the mitochondria.

\section{GLYCOGEN SYNTHESIS AND DEGRADATION}

These occur by different pathways.

The initial step is the conversion of glucose by hexokinase to glucose 6-phosphate, which is then re-arranged to form glucose 1-phosphate. The first

TABLE I

CLASSIFICATION OF MAJOR GLYCOGEN STORAGE DISEASES

\begin{tabular}{llll} 
Type & Enzyme Defect & Tissue Affected & Clinical Features \\
\hline I (von Gierke) & Glucose-6-phosphatase & Liver, kidney, gut & $\begin{array}{l}\text { Hepatomegaly, hypoglycaemia, } \\
\text { ketosis, acidosis } \\
\text { Cardiomegaly, heart failure, } \\
\text { enlarged tongue, muscle weakness } \\
\text { death in infancy }\end{array}$ \\
III (limit dextrinosis) & Acid maltase & $\begin{array}{l}\text { Generalized, particularly heart, } \\
\text { tongue, brain, WBC } \\
\text { Lepatomegaly, moderate fasting } \\
\text { hypoglycaemia, muscle weakness, } \\
\text { and wasting } \\
\text { Cirrhosis, hepatic failure }\end{array}$ \\
IV (amylopectinosis) & 'Debrancher' & Liver, heart, muscle, RBC, WBC & $\begin{array}{l}\text { Liver, spleen, heart, muscle, } \\
\text { RBC, WBC }\end{array}$ \\
V (McArdle) & 'Brancher' & Skeletal muscle only & $\begin{array}{l}\text { Pain, stiffness, weakness on } \\
\text { exercise only; occasionally } \\
\text { myoglobinuria } \\
\text { Hepatomegaly, moderate fasting } \\
\text { hypoglycaemia }\end{array}$
\end{tabular}


step of glycogen synthesis proper is the formation of uridine diphosphoglucose (UDPG) from glucose 1phosphate. This reaction is reversible, but the next step is the irreversible reaction of UDPG with 'glycogen synthetase', which results in the formation of a chain in which glucose molecules are joined to one another in a 1:4-linkage (Fig. 1). This reaction is stimulated by glucose 6-phosphate and by insulin. When the chains reach a length of about 12 glucosyl units, three or four of the units are transferred from the end of that chain to another chain but there they are attached in a 1:6-linkage in such a way that a branch point is formed (Fig. 1). The sequential interactions of 'glycogen synthetase' and 'branching enzymes' result in the typical branched glycogen molecule which has a characteristic colour and light absorption at $460 \mathrm{~m} \mu$ when stained with iodine.

Glycogen breakdown is initiated by phosphorylase, which successively hydrolyzes all the 1: 4-linkages in a chain, each time producing glucose 1-phosphate, but is incapable of splitting the 1:6-links at branch points. To break through the 1:6 link another enzyme is required, the 'debranching enzyme', which yields a molecule of glucose and through its action exposes another chain of 1:4-linked glucosyl units to the action of phosphorylase. Thus the degradation of glycogen, like its synthesis, requires the sequential interaction of two distinct enzymes and results in the formation of glucose and of glucose 1-phosphate which can be used by the cells for their metabolic requirements. Not all the glycogen is broken down by this mechanism: some of it finds its way into the intracellular lysosomes where it is hydrolysed by $\alpha$-glucosidases to form maltose and glucose.

The identity and quantitative importance in human metabolism of the separate pathways of glycogen synthesis and degradation were only clarified when the specific enzyme defects of the glycogen storage diseases were recognized. Their study emphasizes the contribution which clinical medicine can make to basic biochemistry and the help which can be gained from an understanding of the biochemical processes in the management of patients suffering from metabolic disorders. A measure of the wide interest which their study has aroused is the number of reviews of this subject which have appeared recently (Steinitz, 1967; Brown and Brown, 1968; Hers and van Hoof, 1968; Symposium, Amer J. clin Path., 1968; Mahler, 1969).

TYPE I GLYCOGEN STORAGE DISEASE (GLUCOSE 6-PHOSPHATE DEFICIENCY)

In 1929 von Gierke described the excessive accumulation of glycogen in the liver and kidney in this disease, and in 1952 Cori and Cori demonstrated that there was no glucose 6-phosphatase activity in the liver of affected cases. In the absence of the enzyme, the liver cannot produce glucose by either glycogenolysis or gluconeogenesis (Fig. 2) so that patients are liable to have attacks of profound hypoglycaemia. Prolonged severe hypoglycaemia results in secondary disturbances of lipid metabolism with increased mobilization of fat from adipose tissue and overproduction of cholesterol and ketone bodies in the liver. Normally the liver clears the blood of the lactic acid which has been produced by muscles and other tissues with a high rate of glycolysis and converts it into glucose by the usual pathways of gluconeogenesis. In type I glycogen storage disease the liver itself produces large amounts of lactic acid from glycogen, because when glycogenolysis is stimulated, the glucose 6-phosphate is diverted into the glycolytic pathway; the liver thus accentuates an existing lactic acidosis and further disturbs the acid-base balance of the body. Prolonged severe lactic acidaemia may also lead to retention of uric acid by competition for transport at the renal tubule and may result in the appearance of clinical manifestations of tophaceous gout.

The accumulation of abnormal amounts of glycogen in this disease is confined to the liver, kidney, and intestinal mucosa, ie, tissues which normally show glucose 6-phosphatase activity. Although all these tissues can also metabolize glycogen by other pathways, it would seem that the enzyme is of importance in the control of their glycogen content. In other tissues, such as muscle, which normally possess no glucose 6-phosphatase, there is no excess of glycogen.

Absence of enzyme activity in this disorder has been shown by direct assay of the enzyme in biopsies

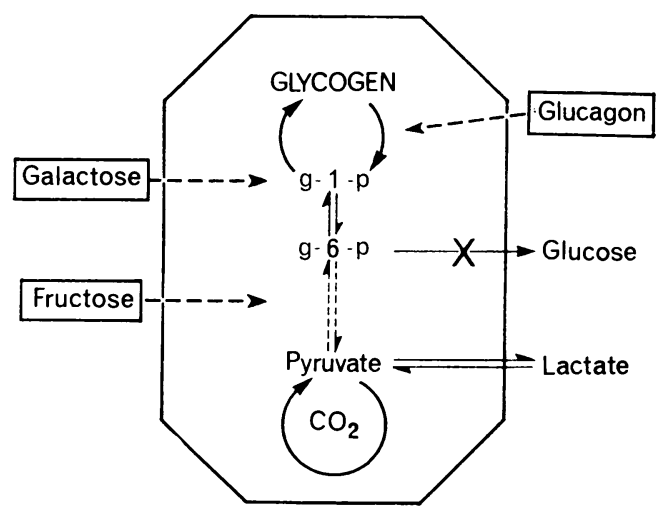

FIG. 2. Type I glycogen storage disease due to glucose 6-phosphatase deficiency $(X)$. 
from liver, kidney, and intestinal mucosa. Indirect evidence for the absence of glucose 6-phosphatase activity in the liver can be obtained from various functional tests: neither the administration of glucagon or adrenaline, both of which stimulate glycogenolysis, nor the administration of galactose or fructose, which are normally converted into glucose by the liver, result in a rise in the blood glucose level, but they produce an abnormal rise in blood lactate.

The prognosis is poor in young children and prevention of hypoglycaemia by frequent meals is important if damage to the brain is to be avoided. Administration of diazoxide, which interferes with the release of insulin from islet cells, also helps to maintain the blood sugar level within a clinically safe range, and rarely more heroic measures, such as the anastomosis of the portal vein to the inferior vena cava so that glucose from the gut bypasses the liver, have been used with some success for this purpose.

Diagnostic tests are summarized in Table II.

BLOOD CHEMISTRY The classical biochemical features of type I glycogenosis are spontaneous hypoglycaemia, persistent ketonaemia, and acidaemia. Hypoglycaemia causes secondary disturbances of lipid metabolism, manifested by raised plasma levels of free fatty acids, cholesterol, and triglycerides; the last may be present in such large amounts that they give the plasma a creamy appearance. Acidaemia is caused by the high concentration of lactic acid, which in turn is responsible for the retention of uric acid in blood.

The glycogen content of red and white blood cells is normal.

FUNCTIONAL TESTS A presumptive differentiation of type I glycogen storage disease from the other types can be made on the proper interpretation of a few, relatively simple, functional tests (Table II). Glucose 6-phosphatase is the enzyme which controls the final common pathway for the release of glucose as the result of glycogenolysis and gluconeogenesis in the liver. In the absence of the enzyme stimulation of these processes cannot result in a rise of the blood glucose level, but the production of lactic acid proceeds freely (Fig. 2).

Glucagon Normally the intramuscular administration of $0.5 \mathrm{mg}$ glucagon, which accelerates glycogen breakdown, causes the blood glucose concentration to increase within 15 to 30 minutes, with only a slight increase in the concentration of lactic acid. In the absence of the enzyme there is no rise in the blood glucose level but a considerable
T A B L E I I

SUMMARY OF THE CLINICAL AND FUNCTIONAL DIFFERENTIATION BETWEEN THE SIX MAJOR TYPES OF GLYCOGEN STORAGE DISEASE

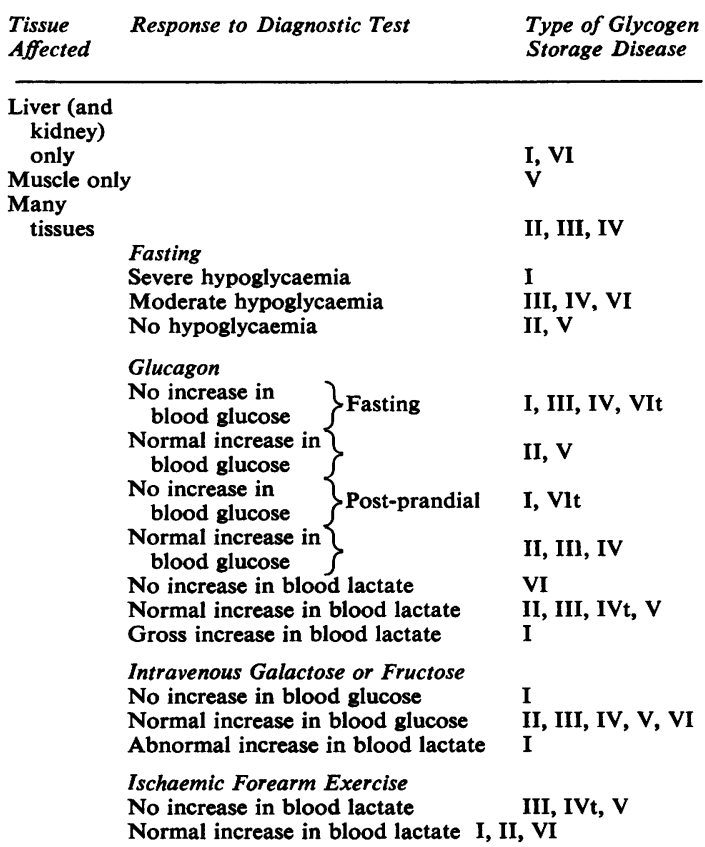

increase in lactic acid, which may be sufficient to aggravate the existing acidosis.

Intravenous infusion of galactose or fructose These two sugars are converted in the liver through a series of enzymatic reactions to glucose 6-phosphate and would then normally be dephosphorylated to glucose and raise the blood glucose level. In the absence of glucose 6-phosphatase there is no increase in blood glucose, but the lactic acid concentration in the blood increases as the result of the metabolism of glucose 6-phosphate through the glycolytic pathway.

The failure of the blood glucose level to rise and the abnormal rise in blood lactate after these two tests differentiates type I from all the other established types of glycogen storage disease.

SPECIFIC INVESTIGATIONS Final proof of the diagnosis, however, must rest on the demonstration of a glycogen content more than $4 \%$ of wet weight and a very low glucose 6-phosphatase activity in a sample of liver obtained by open or needle biopsy.

Estimation of glucose 6-phosphatase activity in intestinal biopsy material is an acceptable alternative to liver biopsy and is the preferred technique for the investigation of relatives of affected patients, levels 
of about $50 \%$ normal being found in heterozygotes. Such studies have shown that the disease is transmitted as an autosomal recessive character.

TYPE II GLYCOGEN STORAGE DISEASE (LYSOSOMAL $\alpha$-GLUCOSIDASE DEFICIENCY)

Although this was one of the earlier types of glycogen storage disease to be recognized as a clinical entity (Pompe, 1932), it is one of the most recent in which a specific enzyme defect has been demonstrated (Hers, 1963). In this disease all the tissues of the body contain large amounts of glycogen which may be sufficient to interfere mechanically with the contractility of the heart muscle and to cause death from heart failure. On the other hand general disturbances of carbohydrate and lipid metabolism are only remarkable by their absence (Fig. 3).

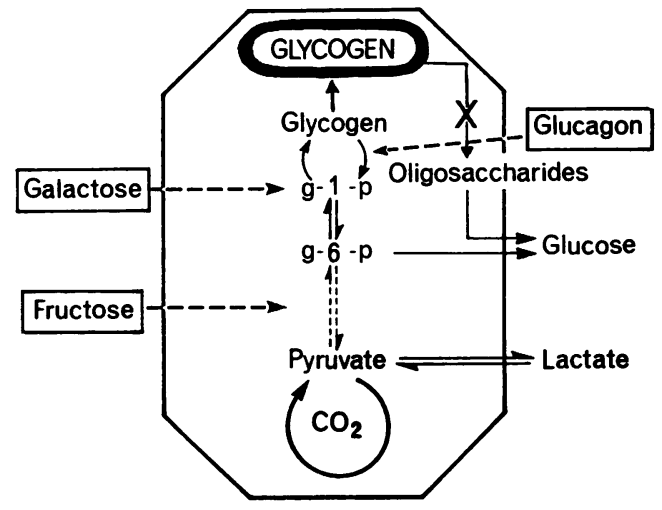

FIG. 3. Type II glycogen storage disease. Glycogen accumulates within lysosomes (heavily outlined) due to absence of 'acid maltase' $(X)$.

In normal cells lysosomes contain a variety of hydrolytic enzymes active at a low $p \mathrm{H}$, which degrade macromolecular compounds such as glycogen, proteins, and lipids which have been engulfed by these organelles (De Duve, 1959). In type II glycogenosis Hers demonstrated the absence of an $\alpha-1: 4$-glucosidase, which normally splits any glycogen enclosed within the lysosome into maltose and glucose. In the absence of the enzyme glycogen accumulates in increasing amounts and with the electron microscope a large aggregation can be seen surrounded by the lysosomal membrane. The structure of the glycogen molecule isolated from the tissues is normal.

It was shown experimentally (Cuthbertson and Fleming, 1964) that a glucosidase derived from Aspergillus niger was capable of lowering liver, muscle, and heart glycogen in the rat after intraperitoneal administration. Baudhuin, Hers, and Loeb (1964) made use of this observation to treat a patient with type II glycogenosis and showed that intramuscular administration of purified fungal $\alpha$-glucosidase decreased the glycogen content of the liver from 11.5 to $8 \%$ (normal level up to about $5 \%$ ).

Diagnostic tests are summarized in Table II.

BLOOD CHEMISTRY There are no recognizable abnormalities of carbohydrate or lipid metabolism.

FUnCTIONAL TESTS All the usual functional tests employed in the investigation of glycogen storage diseases produce normal responses.

SPECIFIC TESTS The diagnosis may be suspected from the unusually high concentration of glycogen found in several tissues (not uncommonly exceeding $10 \%$ of the fresh weight of the tissue). Examination of the tissue under the electron microscope shows that the lysosomes are filled with glycogen granules and that this glycogen persists in the lysosomes when the cells have been exposed to glucagon or adrenaline, although their cytoplasm is depleted of its glycogen content by this treatment.

The diagnosis is confirmed by demonstrating the absence of $\alpha$-1,4-glucosidase in liver or in leucocytes using a biochemical assay devised by Hers (1963). In heterozygous carriers the leucocyte enzyme is reduced.

TYPE III GILYOGEN STORAGE DISEASE ('DEBRANCHING ENZYME' DEFICIENCY)

This disease is characterized by the absence of the 'debranching enzyme', amylo-1 : 6-glucosidase, and an accumulation of a dextrin-like glycogen with abnormally short outer chains. In the absence of the debranching enzyme, phosphorylase acts on successive 1:4-glucosyl linkages in the outer chains of the glycogen molecule, but reaches the limit of its action close to a 1:6-linked branch point, leaving polysaccharide whose structure resembles that of a pollarded tree and is described as a 'limit dextrin' (Fig. 4). The disease is therefore called 'limit dextrinosis'.

The enzyme occurs in most tissues of the body, and accumulations of limit dextrin have been found in many tissues as well as in erythrocytes and leucocytes. Hypoglycaemia occurs on fasting because glycogen can be degraded only to a limited extent, but even then it is rarely severe because glucose can still be formed by gluconeogenetic pathways from amino-acids and other precursors. 


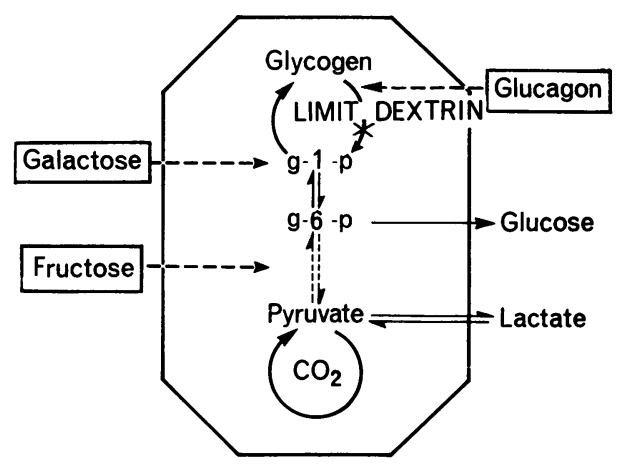

FIG. 4. Type III glycogen storage disease. A limit dextrin accumulates due to limited degrading of glycogen as a result of 'debranching enzyme' deficiency $(X)$.

Detailed studies of the enzyme itself suggest that it consists of a transferase as well as a glucosidase. Two clinical forms of type III glycogenosis have also been described, one affecting the liver and other organs including muscle, the other affecting mainly muscle but not liver, but there is as yet no evidence to show that the clinical distinction is related to the biochemical properties of the enzyme.

The prognosis in this type of glycogen storage disease is much better than in type I and many cases are known to have survived into adult life or have only been discovered accidentally at a later age. It is important to make an accurate diagnosis in order to be able to give an optimistic prognosis with some confidence.

Diagnostic tests are summarized in Table II.

BLOOD CHEMISTRY Hypoglycaemia on fasting, elevated plasma free-fatty acid and occasionally raised plasma cholesterol levels may be observed. The glycogen content of erythrocytes is raised (normal values 20 to $130 \mu \mathrm{g} / \mathrm{g} \mathrm{Hb}$ ).

FUNCTIONAL TESTS These are summarized in Figure 5.

Glucagon In a fasting patient the outer chains of the glycogen molecule have already been 'cropped' as far as a branch point by phosphorylase, so that further stimulation of phosphorylase activity by glucagon remains ineffective and there is no rise in the blood glucose level. After a meal, however, the outer 1:4-linked chains lengthen and now provide a substrate on which phosphorylase can act, so that an injection of glucagon under these conditions can produce an increase in the blood glucose level.

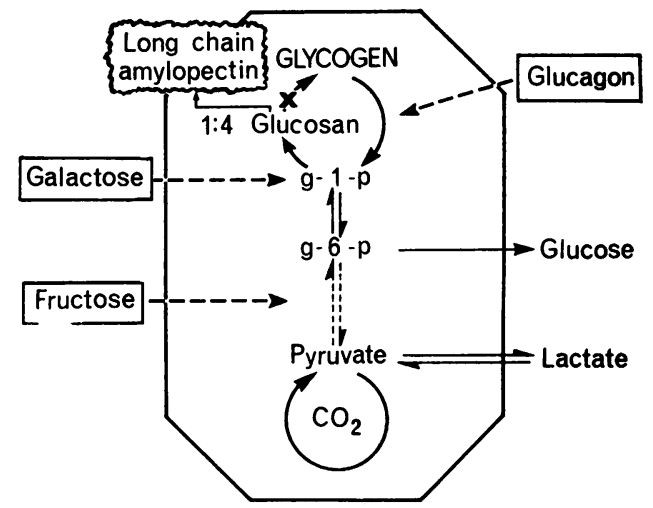

FIG. 5. Type IV glycogen storage disease. A starch-like polysaccharide with few branch points accumulates as the result of 'branching enzyme' deficiency $(X)$.

Infusions of galactose or fructose These result in a normal rise in the blood glucose level because there is no interference with the conversion to glucose of the glucose 6-phosphate, which is formed from these sugars in the liver. There is no abnormal increase in blood lactate.

SPECIFIC INVESTIGATIONS Glycogen isolated fromb tissues or red blood cells can be shown to posses\$ short outer chains of 1,4-linked glucosyl units When stained with iodine, the limit dextrin has light-absorption maximum at $460 \mathrm{~m} \mu$.

The diagnosis is confirmed by carrying out an assay for the debranching enzyme, for which an elegant technique has recently been developed depending upon the release of ${ }^{14} \mathrm{C}$-glucose from labelled glycogen (Hers and van Hoof, 1968).

Heterozygous carriers of the disease can be detected by assay of amylo-1, 6-glucosidase activity in leucocytes or erythrocytes, in which the activity is about $50 \%$ of normal.

TYPE IV GLYCOGEN STORAGE DISEASE ('BRANCHING ENZYME' DEFICIENCY)

Type IV glycogen storage disease is caused by a deficiency of the 'branching enzyme', $\alpha$-1,4-glucan $\rightarrow$ 1,6-transglucosidase, and is characterized by the accumulation of a glycogen with abnormally long outer chains. The outer chains lengthen beyond the normal 8 to 10 glucosyl units, because units continue to be joined in 1,4-linkages through the action of 'glycogen synthetase' without the formation of branch points (Fig. 5). The accumulation of this material in the liver is associated with the development of cirrhosis, progressing to portal hypertension and hepatic failure early in life. 
It appears to be a rare form of glycogen storage and so far only six cases have been described in the literature (Andersen, 1952; Sidbury, Mason, Burns, and Ruebner, 1952; Brown and Brown, 1966; Holleman, van der Haar, and de Vaan, 1966; Fernandes and Huijing, 1968; Levin, Burgess, and Mortimer, 1968). The clinical features of the disease are predominantly those of portal hypertension and cirrhosis. Deposits of the abnormal glycogen occur also in several other tissues, including the spinal cord, and in leucocytes and erythrocytes.

The structure of the glycogen in this disease resembles that of starch and, like starch, it is relatively insoluble in water and stains blue with iodine. The disease is therefore sometimes called 'amylopectinosis'.

All the patients described have died early in life with a cirrhotic liver. An attempt has been made to prevent the development of cirrhosis by treatment with steroids (Sidbury et al, 1962). More recently in another patient liver glycogen was reduced by the intramuscular administration of a purified fungal $\alpha$-glucosidase (Fernandes and Huijing, 1968), but in this case cirrhosis was already far advanced before treatment with the enzyme was begun.

Diagnostic tests are summarized in Table II.

BLOOD CHEMISTRY There are no disturbances of carbohydrate or lipid metabolism and the pattern of liver damage dominates the picture. Red cell and white cell glycogen concentration is raised.

FUNCTIONAL TESTS These (Fig. 5) are distorted to a varying degree by the liver damage, but the result of stimulation of glycogenolysis by glucagon and of gluconeogenesis from galactose and fructose is probably normal, as would be expected.

SPECIFIC TESTS Glycogen, isolated from tissues or blood cells, gives a lavender colour when stained with iodine and can be identified spectrophotometrically by its peak absorption of light at $550 \mathrm{~m} \mu$ in contrast to that of the normally branched glycogen-iodine complex which has an absorption peak at $460 \mathrm{~m} \mu$.

Confirmation of the diagnosis is obtained by determining 'branching enzyme' activity which is measured by the extent to which glucose 1-phosphate is polymerized when it is incubated with a tissue homogenate.

TYPE V GLYCOGEN STORAGE DISEASE (MUSCLE PHOSPHORYLASE DEFICIENCY)

Type $\mathrm{V}$ glycogenosis is confined entirely to skeletal muscle which contains a moderate excess of normally

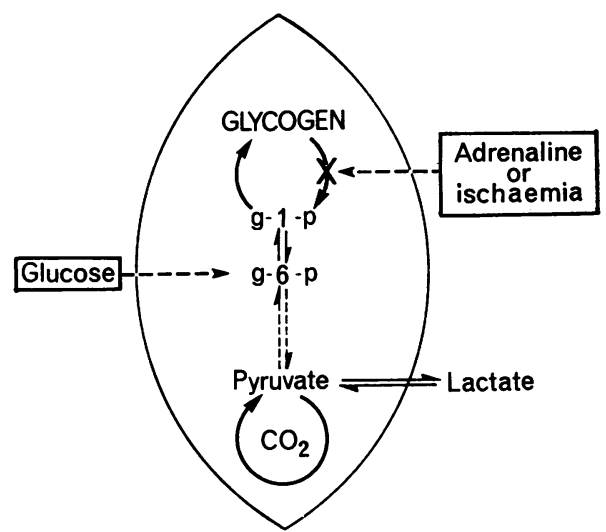

FIG. 6. Type $V$ glycogen storage disease. In muscle glycogen accumulates and lactic acid is not produced by adrenalin or ischaemia as a result of muscle phosphorylase deficiency $(X)$.

structured glycogen. It is caused by a deficiency of phosphorylase (Schmid and Mahler, 1959; Mommaerts, Illingworth, Pearson, Guillory, and Seraydarian, 1959) (Fig. 6).

A thorough clinical description of the first case and the demonstration of the defect in glycolysis in the patient's muscles was given by McArdle (1951) and at least 30 more cases have been reported in the literature in the last 10 years. The striking clinical features are the development of pain and stiffness in the limbs on exercise, in some cases also the appearance of 'electrically silent' contractures in the muscles, and in several cases myoglobinuria after fairly vigorous exercise. It was believed that the stiffness and contractures on exercise were due to a failure of the production of adenosine triphosphate (ATP) because of impaired glycogenolysis, as occurs in rigor mortis. However, ATP levels in the contracted muscle show little reduction (Rowland, Araki, and Carmel, 1965) and the most recent studies by McArdle and his colleagues (Gruener, McArdle, Ryman, and Weller, 1968) indicate that the contractures may be due to a partial failure by the sarcoplasmic reticulum to reaccumulate calcium during vigorous exercise. 'Blebs' of glycogen are present just internal to the sarcolemma and electron microscopy shows accumulation of glycogen within distorted mitochondria (Gruener et al, 1968).

Phosphorylase activity is the final expression of the integrated action on the enzyme of several activating and inactivating processes (Sutherland and Robison, 1966), but type V glycogenosis has been shown to be due to the absence of the enzyme itself, and not to an inhibition of its action. Absence of the enzyme protein, as opposed to inability to 
detect enzyme activity, was confirmed by using an antiphosphorylase serum (Robbins, 1960); the only other type of glycogen storage disease in which absence of the specific enzyme protein has been demonstrated in this way is that due to phosphofructokinase deficiency but it is reasonable to assume, though not proven, that in the other types of glycogen storage disease the specific enzyme protein is also absent.

BLOOD CHEMISTRY At rest, there is no abnormality of carbohydrate or lipid metabolism.

FUNCTIONAL TESTS After exercise, and especially if it has been performed under relatively ischaemic conditions, there is a complete absence of a rise of lactic acid concentration in venous blood draining the ischaemic muscle (Fig. 6). After the exercise the extraction of glucose and fatty acids from blood flowing through the exercised muscles is greatly increased.

Glucagon The blood glucose concentration rises in a normal manner after the injection of glucagon because it stimulates liver phosphorylase, which is immunologically distinct from the muscle enzyme (Henion and Sutherland, 1957) and therefore may be presumed to be under separate genetic control.

There is a normal rise in the blood glucose concentration after an intravenous infusion of fructose or galactose.

SPECIFIC TESTS Muscle biopsies contain a moderate excess of glycogen of normal structure. Phosphorylase assay in muscle shows that there is no enzyme activity, even after the addition of adenosine 5monophosphate which activates the inactive form of phosphorylase. No lactic acid is formed when a muscle homogenate is incubated without added substrate, and the block can only be at a level above glucose 1-phosphate because lactic acid is produced from all the phosphorylated intermediate compounds of carbohydrate metabolism.

Patients can undertake a fair amount of additional exercise if, beforehand, their plasma glucose or free fatty acid levels are raised by suitable means so that these substances can provide the fuel necessary for the exercise.

TYPE VI GLYCOGEN STORAGE DISEASE (LIVER PHOSPHORYLASE DEFICIENCY)

This type of glycogen storage disease is not as clearly defined as any of the preceding types in terms of its enzymatic defect. It is probably best considered as a group of disorders (Fig. 7) in which an excess of glycogen in the liver is associated with

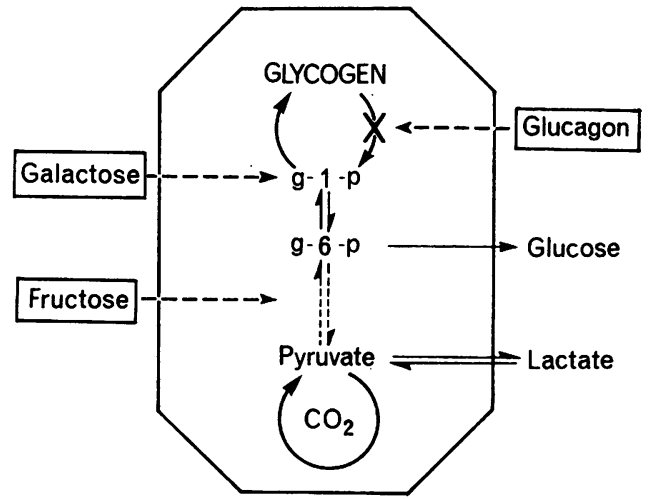

FIG. 7. Type VI glycogen storage disease. In liver glycogen accumulates as a result of diminished liver phosphorylase activity $(X)$.

diminished liver phosphorylase activity (Hers and $N$ van Hoof, 1968)). It is noteworthy that in this type enzyme activity is diminished but not totally absent. In this respect type VI glycogenosis differs from all the other types.

About a third of all cases of glycogen storage disease affecting primarily the liver appear to fall into this rather ill-defined group in which hepatomegaly and moderate hypoglycaemia on fasting are the main clinical features. In several patient who had attacks of severe hypoglycaemia, an ado ditional enzyme defect was found, such as glucose 6-phosphatase deficiency (Sokal, Lowe, Sarcione, Mosovich, and Doray, 1961) or glycogen synthetase deficiency (Parr, Teree, and Larner, 1965). Leucocyte phosphorylase is similar to liver phosphorylase in many respects and this too is low in patients with hereditary deficiency of liver phosphorylase, but activity of the immunologically distinct muscle phosphorylase is not affected.

Like muscle phosphorylase, liver phosphorylase activity is the end result of activating and inactivating reactions affecting the enzyme, and in at least one patient low 'phosphorylase activity' was due not to a defect of the enzyme itself but to a defect of phosphorylase-kinase (Hug, Schubert, Chuck, and Garancis, 1967) which plays a part in converting phosphorylase from the inactive to the active form.

BLOOD CHEMISTRY Moderate hypoglycaemia on fasting is the only notable deviation from normal.

FUNCTIONAL TESTS These consisted of the responses to glucagon and galactose infusion.

Glucagon A poor hyperglycaemic response is usually obtained but there are many exceptions to this rule and even in the same patient the response may be poor on some occasions and normal in others. 
Galactose infusion A normal hyperglycaemic response is obtained unless an additional defect of glucose 6-phosphatase is present.

SPECIAL TESTS High glycogen content and low phosphorylase activity in the liver provides reasonable grounds for making a diagnosis of type VI glycogenosis. However, as there is no sharp upper limit for a normal liver glycogen content, nor a sharp lower limit for phosphorylase activity, it is difficult to define precisely the limits of type VI glycogen storage disease.

\section{OTHER GLYCOGEN STORAGE DISEASES}

In a multienzyme system such as that concerned with carbohydrate metabolism it is not surprising that several other metabolic blocks should have been discovered associated with an abnormal accumulation of glycogen.

The two diseases which are convincingly documented are phosphofructokinase deficiency (Tarui, Okuno, Ikura, Tanaka, Suda, and Nishikawa, 1965; Layzer, Rowland, and Ranney, 1967) and phosphoglucomutase deficiency (Illingworth and Brown, 1964).

PHOSPHOFRUCTOKINASE DEFICIENCY The clinical manifestations of this disease are similar to those of type $\mathrm{V}$ glycogenosis and are presumably the result of diminished energy production due to interference with the normal glycolytic pathway (Fig. 8). This is one of the few inherited metabolic diseases in which absence of the enzyme protein has been demonstrated by the use of an antiserum to the enzyme (Layzer et al, 1967).

Blood chemistry There is no abnormality at rest.

Response to glucagon There is no interference with glucose production by the liver and therefore there is a normal hyperglycaemic response after an injection of glucagon.

Galactose infusion results in a normal rise of blood glucose level.

Ischaemic forearm exercise Glycolysis cannot proceed beyond fructose 1-phosphate, therefore no lactate is formed when ischaemic exercise is undertaken.

Special tests Confirmation of the diagnosis is obtained by measuring the activity of the enzyme and by demonstrating that lactic acid cannot be formed from fructose 1-phosphate or any higher phosphorylated intermediate of the EmbdenMeyerhof pathway, but that it can be formed from fructose 1,6-diphosphate and subsequent intermediate metabolites. These tests prove the absence

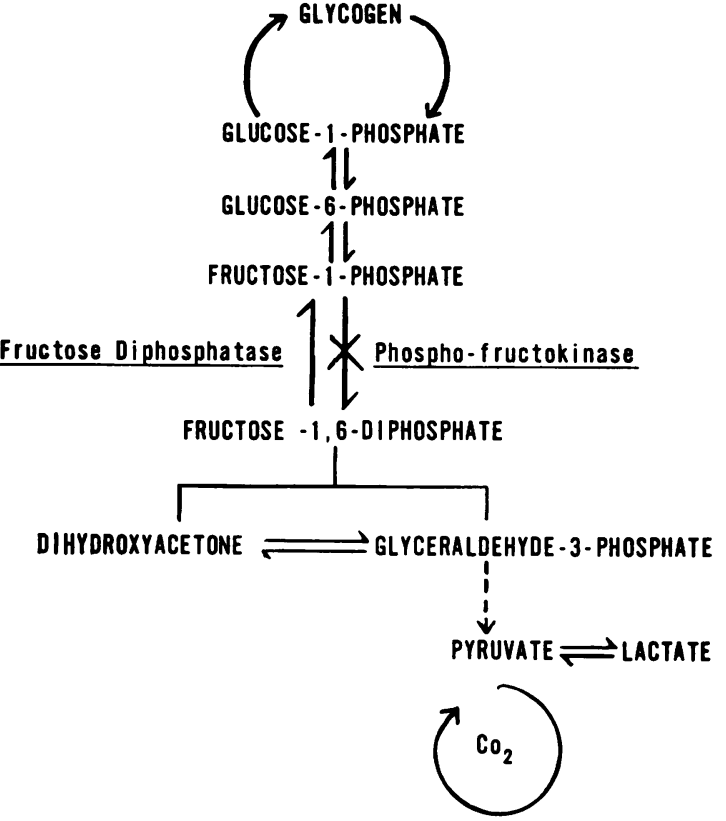

FIG. 8. Phosphofructokinase deficiency $(X)$ prevents lactic acid formation.

of enzyme activity; absence of the enzyme itself can be demonstrated with an immunological technique employing an antiserum to the enzyme.

PHOSPHOGLUCOMUTASE DEFICIENCY The only patient in whom this enzyme defect has been demonstrated directly by enzyme assay had an enlarged liver with a high glycogen content (Illingworth and Brown, 1964). Deficiency of this enzyme poses interesting and as yet unsolved problems concerning the pathways of glycogen synthesis, because the enzyme is essential for the formation of glucose 1-phosphate which is usually held to be the immediate substrate for intracellular glycogen synthesis.

GENERAL IMPLICATION OF STUDIES ON GLYCOGEN STORAGE DISEASES

In his monograph on 'Inborn errors of metabolism' Garrod (1909) developed the concept that in such disorders the normal course of metabolism is blocked by the congenital deficiency of a specific enzyme. In human disease the first direct proof of this concept was the demonstration by Cori and Cori (1952) of a deficiency of glucose 6-phosphatase as the cause of type I glycogen storage disease. This discovery initiated wide interest in enzymological studies of human tissue and has led to the recognition of an ever increasing number of inherited 
metabolic diseases (Stanbury, Wyngaarden, and Fredrickson, 1966). The Coris' discovery led directly to a new and better understanding of the whole group of glycogen storage diseases and made it possible to give an accurate prognosis and institute appropriate therapeutic measures based on an understanding of the underlying metabolic abnormality.

With the discovery of the enzymatic abnormality in type II glycogen storage disease, the concept of 'lysosomal disease' has received serious attention. van Hoof and Hers (1964) have postulated that Hurler's disease may also be an example of an inborn lysosomal disease, in which the metabolism of mucopolysaccharides is primarily affected, and recent experimental work has shown that damage to lysosomes by drugs during foetal development can lead to congenital malformations. Thus studies in glycogen storage disease have cast light on a new approach to the study of disease in general.

The remarkable observation that an enzyme, when injected intraperitoneally into an experimental animal, or intramuscularly in patients with type II and type III glycogen storage disease, can reduce the amount of intracellular glycogen, may have farreaching consequences for the treatment of many diseases, particularly those in which a specific enzyme defect can be demonstrated. There are still many general problems to be solved, such as the mechanisms whereby the enzyme gains entrance to the cell in an active form, and the suppression of the immune response to the enzyme protein, but even the moderate success achieved by this technique in the glycogen storage diseases encourages further work on these lines.

The recognition of the enzyme defect in type $V$ glycogenosis is a particularly striking illustration of the way in which clinical medicine and biochemistry depend upon each other. McArdle's disease is the first example of a myopathy which has been shown to be clearly related to the absence of a single, specific enzyme. On the other hand, the presence of excess glycogen in the muscle proved that the then recently discovered pathway of glycogen synthesis via 'glycogen synthetase' is of importance in man, that glycogen synthesis and glycogen degradation proceed largely by separate pathways and that the action of phosphorylase in vivo is irreversible for all practical purposes. This cleared up the hitherto inexplicable observation that stimulation of phosphorylase activity in vivo by glucagon or adrenaline inevitably leads to loss of glycogen, instead of reaching an equilibrium as would be expected on the basis of reversible enzyme kinetics.

The study of the glycogen storage diseases has been of importance in genetic investigations, and the development of accurate and sensitive enzyme assays has made it possible to identify clinically unaffected heterozygous carriers of a recessive gene. In the last few years a number of cases have been reported in which more than one enzyme appears to be missing. If these observations are correct and not due to a technical fault in the estimation of the enzymes involved, then further thought must be given to the 'one gene, one enzyme' theory. There are a number of possible explanations for these observations, based on genetic mechanisms or on protein polymorphism, but further research in this field is needed.

The glycogen storage diseases, like other inherited metabolic diseases, may be natural experiments in evolution and, because they upset the usual complex self-regulatory mechanisms of the cell, they present a unique opportunity for studying intracellular biochemical processes.

\section{REFERENCES}

Andersen, D. H. (1952). In Carbohydrate Metabolism, edited by V. A. Najjar, p. 28. John Hopkins Press, Baltimore.

Baudhuin, P., Hers, H. G., and Loeb, H. (1964). Lab. Invest., 13, 1139.

Bernard, C. (1857). C.R. Acad. Sci. (Paris), 44, 578.

Brown, B. I., and Brown, D. H. (1966). Proc, nat. Acad. Sci. (Wash.), 56,725 .

(1968). In Carbohydrate Metabolism and its Disorders edited by F. Dickens, P. J. Randle, and W. J. Whelan, vol. 20 p. 123. Academic Press, London.

Cori, G. T., and Cori, C. F. (1952). J. biol. Chem., 199, 661.

Cuthbertson, W. F. J., and Fleming, I. D. (1964). Biochem. J., 92 53P.

De Duve, C. (1959). In Subcellular Particles, edited by T. Hayashi, p. 128. Ronald Press, New York.

Fernandes, J., and Huijing, F. (1968). Arch. Dis. Childh., 43, 347.

Garrod, A. E. (1909). Inborn Errors of Metabolism. Oxford University Press, London.

von Gierke, E. (1929). Beitr. path. Anat., 82, 497.

Gruener, R., McArdle, B., Ryman, B. E., and Weller, R. O. (1968). J. Neurol. Neurosurg. Psychiat., 31, 268.

Henion, W. F., and Sutherland, E. W. (1957). J. biol. Chem., 224, 477.

Hers, H. G. (1963). Biochem. J., 86, 11.

- and van Hoof, F. (1968). In Carbohydrate Metabolism and its Disorders, edited by F. Dickens, P. J. Randle, and W. J. Whelan, vol. 2, p. 151. Academic Press, London.

Holleman, L. W. J., van der Haar, J. A., and de Vaan, G. A. M. (1966). Lab. Invest., $15,357$.

van Hoof, F., and Hers, H. G. (1964). C.R. Acad. Sci. (Paris), 259, 1281 .

Hug, G., Schubert, W. K., Chuck, G., and Garancis, J. C. (1967). Amer. J. Med. 42, 139

Illingworth, B., and Brown, D. H. (1964). In Control of Glycogen Metabolism (Ciba Foundation Symposium), edited by W. J. Whelan and M. P. Cameron, p. 346. Churchill, London.

Layzer, R. B., Rowland, L. P. and Ranney, H. M. (1967). Arch. Neurol., 17, 512.

Levin, B., Burgess, E. A., and Mortimer, P. E (1968). Arch. Dis. Childh., 43, 548

McArdle, B. (1951). Clin. Sci., 10, 13.

Mahler, R. (1969). In Biochemical Disorders in Human Disease, 3rd ed., edited by R. H. S. Thompson and I. D. P. Wootton. Churchill, London.

Mommaerts, W. F. H. M., Illingworth, B., Pearson, C. M., Guillory, R. J., and Seraydarian, K. (1959). Proc. nat. Acad. Sci. (Wash.), 45, 791.

Parr, J., Teree, T. M., and Larner, J. (1965). Pediatrics, 35, 770.

Pompe, J. C. (1932). Ned. T. Geneesk., 76, 304.

Robbins, P. W. (1960). Fed. Proc., 19, 193. 
Rowland, L. P., Araki, S., and Carmel, P. (1965). Arch. Neurol. (Chic.), 13, 541.

Schmid, R., and Mahler, R. (1959). J. clin. Invest., 38, 2044.

Sidbury, J. B., Jr, Mason, J., Burns, W. B., Jr, and Ruebner, B. H. (1962). Bull. Johns Hopk. Hosp., 111, 157.

Sokal, J. E., Lowe, C. U., Sarcione, E. J., Mosovich, L. L., and Doray, B. H. (1961), J. clin. Invest, 40, 364.

Stanbury, J. B., Wyngaarden, J. B., and Fredrickson, D. S. (1966).
In The Metabolic Basis of Inherited Disease, 2nd ed., p. ix. McGraw-Hill, New York.

Steinitz, K. (1967). Advanc. clin. Chem., 9, 227.

Sutherland, E. W., and Robison, G. A. (1966). Pharmacol. Rev., 18,145 .

Symposium (1968). In Amer.J. clin. Path., 50, 1.

Tarui, S., Okuno, G., Ikura, Y., Tanaka, T., Suda, M., and Nishikawa, M. (1965). Biochem. biophys. Res. Commun., 19, 517. 